\section{LDL apheresis in the treatment of non- arteritic ischaemic optic neuropathy: a 6-month follow-up study}

S Guerriero', G Giancipoli', A Cantatore', G Sacco', P Brescia², MT Saliani² and A Ramunni
Table 1 Mean deviation (MD) in the two groups

\begin{tabular}{lcrc}
\hline MD & Group 1 & \multicolumn{1}{c}{ Group 2 } & P \\
\hline Addmitted & $-16.53 \pm 10.03$ & $-14.14 \pm 9.42$ & 0.61 \\
Discharged & $*-11.08 \pm 6.51$ & $-17 \pm 5.24$ & 0.05 \\
After 6 months & $-16.83 \pm 10.72$ & $-13.56 \pm 3.60$ & 0.41
\end{tabular}

${ }^{*} P=0.039$, within group, between admission, and hospital discharge.

In previous experiences, we have associated treatment with LDL apheresis and traditional therapy in patients affected by NAION, obtaining convincing results in terms of the improvement of functional parameters. ${ }^{3-5}$

In this study, 20 patients affected by NAION were randomly subdivided into two groups: a group of 10 patients treated with conventional therapy in combination with LDL apheresis (group 1) and a control group of 10 patients treated with conventional therapy only (group 2).

The comparison of the best-corrected visual acuity at admission, at discharge, and at 6 months in the two groups did not reveal any significant differences within groups and between groups at the times considered.

The mean deviation (MD) resulted statistically significantly improved in group 1 at discharge as compared with admission $(P=0.039)$. However, the improvement did not persist up to 6 months, but returned to the values recorded at hospital admission. Instead, in group 2, the MD remained largely unchanged at all three times considered (Table 1).

The temporary increase in the functional visual parameters that we observed after apheresis seems to be attributable to an
${ }^{1}$ Division of Ophthalmology, Department of Ophthalmology and Otorhinolaryngology, University of Bari, Bari, Italy

${ }^{2}$ Division of Nephrology, Department of Internal and Public Medicine, University of Bari, Bari, Italy

Correspondence:

A Ramunni,

Division of Nephrology,

Department of Internal and

Public Medicine,

University of Bari,

Piazza Giulio Cesare,

11, Bari 70124,

Italy

Tel: + 390805478 383;

Fax: + 390805478675

E-mail: a.ramunni@

nephro.uniba.it

Received: 3 April 2008 Accepted in revised form: 26 August 2008; Published online: 19 September 2008 the optic nerve head has been postulated as the cause. $^{1,2}$ 
to be ascertained could achieve a definitive cure of NAION.

\section{References}

1 Arnold AC. Pathogenesis of nonarteritic anterior ischemic optic neuropathy. J Neuroophthalmol 2003; 23: 157-163.

2 Hayreh SS. Anterior ischemic optic neuropathy I: terminology and pathogenesis. Br J Ophthalmol 1974; 58: 981-989.

3 Ramunni A, Giancipoli G, Saracino A, Guerriero S, Saliani MT, Gentile MC et al. LDL-apheresis in acute anterior ischemic optic neuropathy. Int J Artif Organ 2004; 27: 337-341.

4 Ramunni A, Giancipoli G, Guerriero S, Lapenna L, Saracino A, Saliani MT et al. LDL-apheresis accelerates the recovery of nonarteritic acute anterior ischemic optic neuropathy. Ther Apher Dial 2005; 9(1): 53-58.

5 Ramunni A, Ranieri G, Giancipoli G, Guerriero S, Ria R, Saliani MT et al. Is the efficacy of LDL apheresis in ischemic optic neuropathy linked to a reduction in endothelial activation markers? Blood Purif 2006; 063: 1-8. 